\title{
Air Pollution During Growth: Accounting for Governance and Vulnerability
}

\author{
Susmita Dasgupta* \\ Kirk Hamilton \\ Kiran Pandey \\ David Wheeler
}

World Bank

\begin{abstract}
World Bank Policy Research Working Paper 3383, August 2004
The Policy Research Working Paper Series disseminates the findings of work in progress to encourage the exchange of ideas about development issues. An objective of the series is to get the findings out quickly, even if the presentations are less than fully polished. The papers carry the names of the authors and should be cited accordingly. The findings, interpretations, and conclusions expressed in this paper are entirely those of the authors. They do not necessarily represent the view of the World Bank, its Executive Directors, or the countries they represent. Policy Research Working Papers are available online at http://econ.worldbank.org.
\end{abstract}

Authors' names in alphabetical order. The authors' positions are, respectively, Senior Economist, Development Research Group, World Bank (WB); Lead Economist, Environment Department, WB; Senior Environmental Economist, Global Environment Facility (GEF); and Lead Economist, Development Research Group, WB. Financial support for this study has been provided by the World Bank's Environment Department and Development Research Group. Our thanks to Bart Ostro and WHO colleagues for useful comments and suggestions, and to Piet Buys, for his assistance with GIS applications. 


\begin{abstract}
New research on urban air pollution casts doubt on the conventional view of the relationship between economic growth and environmental quality. This view holds that pollution automatically increases until societies reach middle-income status, because poor countries have neither the institutional capacity nor the political commitment necessary to regulate polluters. Some policymakers and researchers have cited this model (called the "environmental Kuznets curve" (EKC)) when arguing that developing countries should "grow first and clean up later." However, new evidence suggests that the EKC model is misleading because it mistakenly assumes that strong environmental governance is not possible for poor countries. As we show in this paper, the empirical relationship between pollution and income becomes much weaker when measures of governance are added to the analysis. Our results also suggest that previous research has underestimated the effect of geographic vulnerability (climate and terrain factors) on air quality. We find that weak governance and geographic vulnerability alone can account for the crisis levels of air pollution in many developing-country cities. When these factors are combined with income and population effects, we have a sufficient explanation for the fact that some cities already have air quality comparable to levels in OECD urban areas. To summarize, our results suggest that the maxim, "grow first, clean up later" is too simplistic. Appropriate urban growth strategies can steer development toward cities with lower geographic vulnerability, and governance reform can reduce air pollution significantly, long before countries reach middle-income status.
\end{abstract}




\section{Introduction}

The environmental Kuznets curve (EKC) model posits a deterministic relationship between economic development and environmental quality. ${ }^{1}$ In the first stage of industrialization, pollution in the EKC world grows rapidly because people are far more interested in jobs and income than clean air and water, communities are too poor to pay for abatement, and environmental regulation is correspondingly weak. The balance shifts as income rises. Leading industrial sectors become cleaner, people value the environment more highly, and regulatory institutions become more effective. Along the curve, pollution levels off in the middle-income range and then falls toward pre-industrial levels in wealthy societies.

Many empirical researchers have accepted the basic tenets of this deterministic model, and have focused on measuring its parameters. Their regressions, fitted to crosssectional observations across countries or regions, typically suggest that air and water pollution increase with development until per capita income reaches a range of $\$ 5,000$ to $\$ 8,000$. When income rises beyond that level, pollution starts to decline. In developing countries and donor institutions, some policy-makers have interpreted such results as conveying an important message about priorities: Grow first, then clean up.

If the $\mathrm{EKC}$ model is correct, the environment prospects are extremely poor for many developing countries. According to the most recent World Bank estimates, average per capita GDP in 2002 was \$449 in 59 low-income countries and \$1,786 in 52 lower-middle income countries. ${ }^{2}$ These countries are nowhere near the maximum pollution point on the conventional EKC curve so, in this model, they are fated to endure rising pollution and

\footnotetext{
${ }^{1}$ Kuznets' name was apparently attached to the curve by Grossman and Krueger (1993), who noted its resemblance to Kuznets' inverted-U relationship between income inequality and development.

${ }^{2}$ GDP per capita in constant \$US 1995.
} 
natural resource degradation for many decades. Moreover, empirical research suggests that pollution costs are already quite high. For example, recent World Bank estimates of mortality and morbidity from urban air pollution in India and China suggest annual losses in the range of 2-3\% of GDP (Pandey, et al., 2004).

Should we believe this model? In fact, numerous critics have challenged the EKC, both as a representation of what actually happens in the development process and as a policy tool. Some critics argue that the EKC is actually too optimistic. Over time, they claim, the curve will rise to a horizontal line at maximum existing pollution levels, as globalization promotes a "race to the bottom," poor countries become pollution havens, and environmental standards collapse in industrial countries as they defend their competitive position. ${ }^{3}$

The pessimists' claims have not been bolstered by much empirical research. In fact, recent empirical work has fostered an optimistic critique of the conventional EKC. The new results suggest that the curve is actually flattening and shifting to the left, as growth generates less pollution in the early stages of industrialization and pollution begins falling at lower income levels. ${ }^{4}$ Such work, however, continues to reinforce the deterministic worldview of the EKC model.

\footnotetext{
3 Daly (2000) has forcefully defended the view that trade and investment are affected by pollution havens. At a union convention in 1999, Congressman David Bonior offered the following critique of the World Trade Organization (WTO): "The WTO, as currently structured, threatens to undo internationally everything we have achieved nationally - every environmental protection, every consumer safeguard, every labor victory" (Bonior 1999). In a similar vein, the Nader-for-President 2000 campaign characterized the North American Free Trade Agreement as follows: "Such one-dimensional monetized logic tramples longstanding efforts around the world-some very successful-to protect the environment because environmental safeguards are very often considered 'non-tariff barriers to trade' and thus become targets for removal." (Nader 2000). Critics of trade liberalization have also raised the prospect of agricultural pollution havens, where low-cost production with unregulated pesticide use poisons agricultural workers, as well as consumers in countries that import their contaminated produce (Sagaris 1999; and Rauber 1997).

${ }^{4}$ See Dasgupta, et al. (2000).
} 
In this paper, we present new evidence on pollution and development which casts doubt on the EKC approach. Our research suggests that most EKC models are misleading because they exclude two important factors that have been hard to quantify: governance and vulnerability to environmental damage. New evidence on governance suggests that the EKC's deterministic link between income and policy is simply wrong: Some poor countries have strong policy performance, and some middle-income countries are weak in this dimension. As we will demonstrate in this paper, governance has strong, independent effects on environmental quality. Since governance is positively correlated with income, exclusion of governance from EKC regressions automatically inflates the importance of income as a determinant of pollution.

The other frequently-excluded factor is local vulnerability to environmental damage. Conceptually, the basic EKC model posits a world of homogeneous economies operating on the same featureless plain. In reality, environmental outcomes can be significantly affected by the sectoral composition of economic activity, as well as the geographic features of each locus of activity. Using newly-available data, we incorporate these factors into a more complete model of environmental change.

The remainder of the paper is organized as follows. Section 2 reviews recent research on economy-environment links, with a particular focus on pollution. Sections 3 and 4 introduce new evidence on factors that have often been excluded from EKC research: governance, local vulnerability and the sectoral composition of economic activity. In section 5, we incorporate these factors into an econometric analysis of the most recent international evidence on air pollution. Section 6 employs simulation to 
explore the implications of our findings, and Section 7 provides a summary and conclusions.

\section{Theoretical and Empirical Work on the $\mathbf{E K C}^{5}$}

Theoretical papers on the EKC have derived transition paths for pollution, abatement effort and development under alternative assumptions about social welfare functions, pollution damage, the cost of abatement, and the productivity of capital. This research has shown that an inverted-U EKC can arise under the following conditions: As income increases in a society, the marginal utility of consumption is constant or falling; the disutility of pollution is rising; the marginal damage of pollution is rising; and the marginal cost of abating pollution is rising. Most theoretical models do not incorporate governance quality, since they implicitly assume the existence of a public agency that regulates pollution with full information about the benefits and costs of pollution control. They seldom incorporate variations in vulnerability to environmental damage, and they generally assume that the pollution externality is local, not cross-border. In the latter case, there would be little local incentive to internalize the externality.

Lopez (1994) demonstrates that if producers pay the social marginal cost of pollution, then the relationship between emissions and income depends on the properties of technology and preferences. Under homothetic preferences, an increase in output will result in an increase in pollution. If preferences are nonhomothetic, however, the response of pollution to growth will depend on the degree of relative risk-aversion and the elasticity of substitution in production between pollution and conventional inputs.

\footnotetext{
5 This section draws heavily on Dasgupta, et al. (2002).
} 
Selden and Song (1995) derive an inverted-U curve for the relationship between optimal pollution and the capital stock, assuming that optimal abatement is zero until a given capital stock is achieved, and that it rises thereafter at an increasing rate. John and Pecchenino (1994), John et al. (1995), and McConnell (1997) derive similar inverted-U curves by using overlapping generations models. In an interesting departure that has particular significance for this paper, Lopez and Mitra (2000) analyze the effect of governance on environmental quality. Their theoretical results show that for any level of per capita income, the pollution level corresponding to corrupt behavior is always above the socially optimal level. Further, they show that the turning point of the environmental Kuznets curve takes place at income and pollution levels above those corresponding to the social optimum.

Numerous empirical studies have tested the EKC model. Most have regressed cross-country measures of ambient air and water quality on various specifications of income per capita. These studies often rely on air pollution data from the Global Environmental Monitoring System (GEMS), an effort sponsored by the United Nations. Stern, et al. (1998) have supplemented the GEMS data with a more detailed accounting of airborne sulfur emissions. Although greenhouse gases have not been included in the GEMS database, carbon dioxide emissions estimates for most developed and developing countries are available from the U.S. Oak Ridge National Laboratories (Marland, Boden and Andres, 2001).

Empirical researchers are far from agreement that the EKC provides a good fit to the available data, even for conventional pollutants. In a review of the empirical literature, Stern (1998) argues that the evidence for the inverted-U relationship applies only to a subset 
of environmental measures; for example, air pollutants such as suspended particulates and sulfur dioxide. Since Grossman and Krueger (1993) find that suspended particulates decline monotonically with income, even Sterns' subset is open to contest. In related work, Stern, et al. (1998) find that sulfur emissions increase through the existing income range. Results for water pollution are similarly mixed. Even without incorporating other factors, then, the EKC seems to provide an uncertain basis for understanding environmental quality changes in developing countries.

\section{Environmental Governance}

Although theoretical and empirical work on the EKC has largely ignored governance, attempts to measure its effectiveness are now well-advanced. For example, the World Bank has committed itself to an annual, quantitative assessment of country policies and institutional capacity for environmental governance. ${ }^{6}$ The World Bank's CPIAE (Country Policy and Institutional Assessment for Environment) rates countries from 1 to 6 , in ascending order of effectiveness in environmental governance. Table 1 tabulates the most recent CPIAE ratings by income group for 134 developing and newlyindustrialized countries. As the table shows, the CPIAE rises moderately with income, from a mean rating of 2.9 for low-income countries to 4.2 for upper-middle-income countries. However, the detailed tabulation of ratings indicates the actual degree of dispersion: low-income countries vary from 1 to 4.5; lower-middle income countries from 2.5 to 4.5 , and upper-middle income countries from 2.5 to $6 .^{7}$

\footnotetext{
6 For related work at other institutions, see Esty and Cornelius (2002).

7 For 136 countries, bivariate linear and log regressions of the environmental institutions rating on GDP per capita yield $\mathrm{R}^{2}$ 's of only .32 and .29 , respectively.
} 
Table 1: Distribution of Institutional Capacity Rating By World Bank Income Group

\begin{tabular}{|l|l|l|r|r|r|r|r|r|r|r|r|}
\hline & \multicolumn{1}{|c|}{$\begin{array}{l}\text { No. of } \\
\text { Countries }\end{array}$} & $\begin{array}{l}\text { Mean } \\
\text { Income Group }\end{array}$ & \multicolumn{7}{|c|}{ Capacity Rating for } \\
\hline & & & $\mathbf{1}$ & $\mathbf{2 . 5}$ & $\mathbf{3}$ & $\mathbf{3 . 5}$ & $\mathbf{4}$ & $\mathbf{4 . 5}$ & $\mathbf{5}$ & $\mathbf{6}$ \\
\hline & & & \multicolumn{6}{|c|}{ \% by Performance Class } \\
\hline Low income & 58 & 2.89 & 5 & 29 & 43 & 19 & 2 & 2 & 0 & 0 \\
\hline $\begin{array}{l}\text { Lower middle } \\
\text { income }\end{array}$ & 49 & 3.41 & 0 & 10 & 27 & 39 & 20 & 4 & 0 & 0 \\
\hline $\begin{array}{l}\text { Upper middle } \\
\text { income }\end{array}$ & 27 & 4.24 & 0 & 4 & 15 & 15 & 26 & 7 & 19 & 15 \\
\hline Total & 134 & 3.35 & 2 & 17 & 31 & 25 & 13 & 4 & 4 & 3 \\
\hline
\end{tabular}

This dispersion may have two sources. On the "supply side," the effectiveness of environmental institutions may reflect overall institutional effectiveness, which may in turn reflect a variety of social and political factors that correlate only roughly with development. On the "demand side," countries with more serious environmental problems may devote more resources to environmental institutions, given their levels of income and overall institutional effectiveness. In any case, the ratings in Table 1 suggest an important message: Low levels of development do not prevent countries from having effective environmental institutions and policies.

\section{Vulnerability to Pollution}

\subsection{Geographic Factors}

This paper focuses particularly on suspended particulate matter created by combustion and other processes, since inhalation of these particles creates much of the human health damage attributed to air pollution. ${ }^{8}$ Intuitively, it seems likely that once small particles are emitted, they will stay airborne for shorter periods in areas that are rainy and windy. More subtle factors (temperature, sunshine, air pressure, surrounding

\footnotetext{
${ }^{8}$ For a review of the evidence, see Pandey, et al. (2004).
} 
terrain) may also affect the airborne suspension of particulates. Using information from thousands of air-quality monitoring reports, a recent World Bank - WHO study has provided the first systematic quantification of these factors (Pandey, et al, 2004). The study has combined their estimated impacts into a vulnerability index for approximately 3,200 world cities whose population exceeds 100,000.

The results suggest great variation in the atmospheric impact of fine-particulate emissions. Across cities, the $1^{\text {st }}$-and $99^{\text {th }}$-percentile index values are 15 and 83 , respectively. By implication, the impact of particulate emissions varies more than fivefold from cities with the least natural vulnerability to those with the most. Vulnerability is highly varied, both within and across regions: All continents have regions of low and high vulnerability.

\section{Table 2: World Urban Population (Millions) By Geographic Vulnerability and Income}

\begin{tabular}{|l|r|r|r|r|}
\hline & \multicolumn{3}{|c|}{ World Bank } & Total \\
\hline Vulnerability & \multicolumn{3}{|c|}{ Income Group } & \multicolumn{1}{c|}{. } \\
\hline & 8 & 25 & 12 & 45 \\
\hline $0-20$ & 93 & 193 & 194 & 480 \\
\hline $21-40$ & 133 & 627 & 293 & 1,053 \\
\hline $41-60$ & 150 & 169 & 32 & 351 \\
\hline $61-80$ & 50 & 0 & 0 & 50 \\
\hline $81-100$ & 434 & 1,014 & 530 & 1,978 \\
\hline Total & \multicolumn{4}{|c|}{} \\
\hline
\end{tabular}

Table 2 provides a breakdown of world urban population by atmospheric vulnerability and income group. In low-income countries, approximately 100 million people live in areas whose climates and terrain features indicate low vulnerability $(0-40)$, 130 million live at medium vulnerability (41-60), and 200 million at high vulnerability (61-100). In high-income countries, by contrast, most people live under conditions of low or medium vulnerability. We emphasize that, given the population distribution, these 
conditions are simply given by nature: In high-vulnerability cities (and disproportionately in low-income countries), a unit of particulate emissions pollutes the air much more than in low-vulnerability cities.

\subsection{Economic Structure}

For economic-environmental analysis, measures of aggregate economic output can be very misleading because the composition of output is critical for understanding potential environmental impacts. To illustrate, consider the impact of industrial development on air and water pollution. Intuitively, it seems clear that not all industry sectors are equal sources of environmentally damaging emissions: A shirt factory is not a steel mill. In recent years, we have been able to quantify the dimensions of this difference by industry sector, for a large number of pollutants. ${ }^{9}$ We have found that of twenty-eight industry sectors coded at the 3-digit international classification (ISIC), only seven persistently account for at least $90 \%$ of global emissions for major air and water pollutants. Table 3 displays estimated percent contributions by sector, pollutant and decade. Besides indicating the large aggregate contribution, it indicates even more sectoral concentration for individual pollutants, along with a high degree of stability during the past four decades. ${ }^{10}$

Comparative advantage and government policies have both affected the international distribution of industrial activity during the past several decades.

\footnotetext{
9 For a detailed discussion, see Hettige, et al. (1995).

${ }^{10}$ For the derivation of emissions estimates, see Hettige, Mani and Wheeler (2000).
} 
Table 3: Percent Contribution to Global Industrial Emissions: Seven Industry Sectors

\begin{tabular}{|c|c|c|c|c|c|c|c|c|}
\hline $\begin{array}{c}\text { Industry } \\
\text { Sector } \\
\text { (ISIC Code) }\end{array}$ & $\begin{array}{c}\text { Iron \& } \\
\text { Steel } \\
(371) \\
\end{array}$ & $\begin{array}{c}\text { Petroleum } \\
\text { Refineries } \\
(353) \\
\end{array}$ & $\begin{array}{c}\text { Food } \\
\text { Products } \\
(311)\end{array}$ & $\begin{array}{c}\text { Industrial } \\
\text { Chemicals } \\
(351) \\
\end{array}$ & $\begin{array}{c}\text { Paper \& } \\
\text { Products } \\
(341)\end{array}$ & $\begin{array}{c}\text { Non- } \\
\text { Ferrous } \\
\text { Metals } \\
(372) \\
\end{array}$ & $\begin{array}{c}\text { Cement } \\
(369)\end{array}$ & Total \\
\hline \multicolumn{9}{|l|}{ Air Pollutants } \\
\hline \multicolumn{9}{|l|}{$\begin{array}{l}\text { Particulate Air } \\
\text { Pollution } \\
(\text { PM-10) }\end{array}$} \\
\hline 1960 & 29.0 & 1.4 & 8.5 & 1.6 & 2.2 & 0.7 & 52.5 & 96.0 \\
\hline 1970 & 27.6 & 1.4 & 8.5 & 1.8 & 2.0 & 0.7 & 53.9 & 96.0 \\
\hline 1980 & 25.5 & 1.5 & 8.6 & 2.0 & 1.9 & 0.7 & 55.8 & 96.0 \\
\hline 1990 & 21.8 & 1.0 & 7.9 & 1.8 & 2.0 & 0.7 & 60.3 & 95.4 \\
\hline \multicolumn{9}{|l|}{ Sulfur Dioxide } \\
\hline 1960 & 18.4 & 25.2 & 3.2 & 10.2 & 6.9 & 13.0 & 11.4 & 88.4 \\
\hline 1970 & 17.6 & 25.2 & 3.2 & 11.2 & 6.4 & 12.9 & 11.8 & 88.3 \\
\hline 1980 & 15.8 & 25.3 & 3.1 & 12.7 & 5.8 & 13.3 & 11.9 & 88.0 \\
\hline 1990 & 15.3 & 19.5 & 3.2 & 12.3 & 6.8 & 15.0 & 14.5 & 86.6 \\
\hline \multicolumn{9}{|l|}{ Toxic Chemicals } \\
\hline 1960 & 5.8 & 6.8 & 0.7 & 36.6 & 7.3 & 5.7 & 1.5 & 64.4 \\
\hline 1970 & 5.3 & 6.6 & 0.7 & 38.9 & 6.5 & 5.4 & 1.5 & 65.0 \\
\hline 1980 & 4.6 & 6.4 & 0.7 & 42.7 & 5.7 & 5.4 & 1.5 & 67.0 \\
\hline 1990 & 4.3 & 4.8 & 0.7 & 40.1 & 6.5 & 5.9 & 1.7 & 64.1 \\
\hline \multicolumn{9}{|l|}{ Water Pollutants } \\
\hline \multicolumn{9}{|l|}{\begin{tabular}{l|} 
Biochemical \\
Oxygen \\
Demand
\end{tabular}} \\
\hline 1960 & 0.1 & 2.4 & 32.7 & 21.7 & 28.2 & 7.5 & 0.1 & 92.7 \\
\hline 1970 & 0.1 & 2.4 & 32.9 & 23.8 & 25.8 & 7.4 & 0.1 & 92.5 \\
\hline 1980 & 0.1 & 2.4 & 32.1 & 26.9 & 23.2 & 7.6 & 0.1 & 92.4 \\
\hline 1990 & 0.1 & 1.7 & 31.2 & 24.5 & 25.9 & 8.1 & 0.1 & 91.6 \\
\hline \multicolumn{9}{|l|}{ Toxic Chemicals } \\
\hline 1960 & 10.8 & 2.7 & 1.1 & 67.5 & 9.7 & 1.2 & 0.1 & 93.1 \\
\hline 1970 & 9.8 & 2.6 & 1.0 & 70.5 & 8.5 & 1.1 & 0.1 & 93.6 \\
\hline 1980 & 8.2 & 2.4 & 0.9 & 74.5 & 7.1 & 1.1 & 0.1 & 94.4 \\
\hline 1990 & 8.0 & 1.9 & 1.0 & 73.0 & 8.6 & 1.2 & 0.1 & 93.8 \\
\hline
\end{tabular}


The resulting differences have significant environmental implications: Industrial economies focused on light, labor-intensive assembly (e.g., apparel, electronics, furniture) are far less susceptible to pollution than those with a heavy concentration of activity in the seven "dirty" industry sectors. Rapid growth in the first group may have very modest environmental impacts, while growth in the second may endanger thousands of lives annually.

\section{The EKC Revisited: Accounting for Governance and Vulnerability}

For our empirical work, we focus on one form of air pollution, suspended particulate matter (TSP), because suspended particulates have significant health impacts, and TSP data are available for many developing countries. We compare results for a conventional EKC model, in which the atmospheric concentration of TSP is a function of income per capita alone, and an extended model that includes measures of governance, geographic vulnerability, and the pollution-intensity of industrial activity. In addition, we include two controls for city size: Population, which proxies the scale of local pollutiongenerating activities, and population density, which proxies the space-intensity of the same activities. We also allow for the possibility of an exogenous trend in pollution, reflecting the international diffusion of cleaner technology and (perhaps) environmentalist values during the 1990's.

We employ the latest available TSP dataset from WHO, which includes time series from 1986 to 1999 for 340 individual air quality monitors in 170 cities. Of these, 209 monitors and 85 cities are in developing, newly-industrialized or Eastern European 
countries. For exact comparison over time, we match air quality measures from specific monitors in different periods. ${ }^{11}$

We draw our measures of country income per capita and city population from World Bank and UN databases. We have computed city population densities using a Geographic Information System (GIS), by overlaying a fine-grid map of world population distribution on standard circles whose $20-\mathrm{km}$. radii extend from geographic center points for the cities in our sample. We also use the city-specific geographic vulnerability indices and shares of the seven "dirty" industry sectors that we introduced in Section 4.

Our panel data span 14 years, and we cannot depend on recently-computed World Bank CPIAE ratings to proxy environmental governance since the mid-1980's. The only panel data available for the entire period are country corruption indices published by Transparency International (TI). TI's corruption index for 2003 is highly correlated with the 2003 CPIAE: The linear regression result is CPIAE $=2.06(10.2)+0.48 \mathrm{TI}(8.0) ; \mathrm{R}^{2}$ $=.41 \mathrm{~N}=92$ (t-statistics in parentheses). We therefore employ the TI corruption index for 1986-1999 as our governance proxy. ${ }^{12}$

We compute average values of regression variables for three periods: 1986-90, 1991-95 and 1996-99. Table 4 presents conventional EKC estimates for the three periods, with and without monitor site matching across periods, along with pooled panel

\footnotetext{
${ }^{11}$ Air quality measures can differ substantially across monitors within cities, and across cities within countries. Changing site composition can introduce both random error and systematic bias into intertemporal comparisons using city or country averages, the latter because initially-monitored sites tend to be more polluted than later additions.

${ }_{12}$ Since the TI index reflects perceived corruption, it also provides evidence for testing the previously mentioned corruption-pollution hypothesis of Lopez and Mitra (2000).
} 
estimates for all three periods. ${ }^{13}$ Table 6 presents period and panel estimates for the full set of hypothesized TSP determinants. All regressions are in log form.

Table 4a reports linear and quadratic estimates for the simple EKC model, using non-matched monitoring data to maximize degrees of freedom in each period. The results in $4 \mathrm{a}$ are consistent with the findings in Grossman and Krueger (1993). Across the three sample periods, they suggest a monotonically-declining relationship between income and air pollution. ${ }^{14}$ The estimated elasticity of TSP with respect to income per capita is around -0.4 in all three periods, with very high t-statistics and high regression $\mathrm{R}^{2 \text { s }}$. The results suggest that air pollution declines approximately $0.4 \%$ with each $1 \%$ increase in income per capita.

Tables $4 \mathrm{~b}$ and $4 \mathrm{c}$ use a panel of matched monitoring sites, to preserve comparability across periods. Table $4 \mathrm{~b}$ replicates the period estimates in $4 \mathrm{a}$, and shows that the matched sample fit is very close to the full sample fit in each period: Estimated elasticities are around -0.4, t-statistics are very high, and regression $\mathrm{R}^{2 \text {, }}$ s are around 0.60. Table $4 \mathrm{c}$ presents panel estimates for the pooled sample of matched sites, enabling us to estimate the overall EKC relationship with maximum degrees of freedom. For the OLS and random effects models, the estimated elasticities are again around -0.4 and the regression fit appears quite robust. Our results for the period dummies suggest a significant trend in the matched sample: Compared with TSP concentrations in

\footnotetext{
${ }^{13}$ Degrees of freedom are greater without site matching, since site measures are not always available for all three periods. However, as we noted previously, site matching assures perfectly comparable results across periods.

${ }^{14}$ This is true even for the quadratic regression for 1986-90, which has a significant quadratic term but an insignificant linear term. The scatter of TSP concentration on income for this period is downward-sloping throughout, with some indication of a steeper slope at higher income levels. However, even this apparent relationship disappears in the data (and regression results) for the 1990's.
} 


\section{Table 4: Conventional EKC Estimates}

Dependent variable: $\log$ TSP $\left(\mathrm{ug} / \mathrm{m}^{3}\right)$

\section{a. Monitoring Sites Not Matched}

\begin{tabular}{lllllll} 
& \multicolumn{1}{c}{$(1)$} & $(2)$ & $(3)$ & $(4)$ & $(5)$ & $(6)$ \\
& $86-90$ & $86-90$ & $91-95$ & $91-95$ & $96-99$ & $96-99$ \\
\cline { 2 - 7 } Log GDPPC & 0.482 & -0.367 & -0.142 & -0.434 & 0.148 & -0.424 \\
& $(1.83)$ & $(17.39) * *$ & $(0.51)$ & $(20.38) * *$ & $(0.45)$ & $(17.86) * *$ \\
[Log GDPPC]**2 & -0.054 & & -0.018 & & -0.034 & \\
& $(3.24) * *$ & & $(1.05)$ & & $(1.76)$ \\
Constant & 4.550 & 7.747 & 7.094 & 8.226 & 5.717 & 8.018 \\
& $(4.54) * *$ & $(43.96) * *$ & $(6.50) * *$ & $(46.80) * *$ & $(4.33) * *$ & $(39.28) * *$ \\
Obs & 192 & 192 & 241 & 241 & 236 & 236 \\
R-squared & 0.63 & 0.61 & 0.64 & 0.63 & 0.58 & 0.58
\end{tabular}

b. Period Regressions: Monitoring Sites Matched

\begin{tabular}{llll} 
& $86-90$ & $91-95$ & $96-99$ \\
\cline { 2 - 4 } Log GDP Per Capita & -0.342 & -0.401 & -0.417 \\
& $(11.99) * *$ & $(15.18) * *$ & $(13.65) * *$ \\
Constant & 7.526 & 7.879 & 7.961 \\
& $(31.65) * *$ & $(35.80) * *$ & $(30.97) * *$ \\
Observations & 122 & 122 & 122 \\
R-squared & 0.54 & 0.66 & 0.61
\end{tabular}

c. Balanced Panel Regressions (Monitoring Sites Matched)

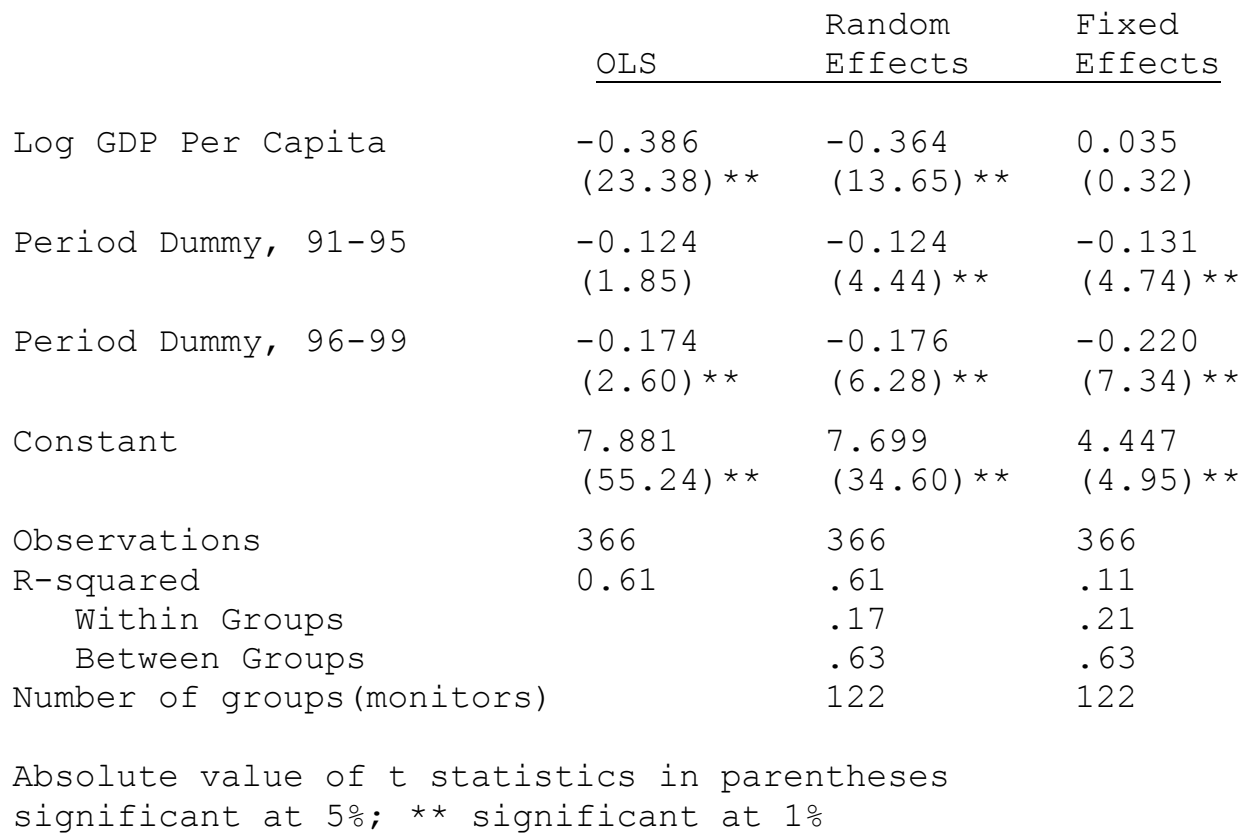


1986-90 (ceteris paribus), overall concentrations are .12 log units lower in 1991-95 and $.18 \log$ units lower in 1996-1999.

The fixed-effects results in the third column of Table $4 \mathrm{c}$ introduce controls for all 122 monitoring sites in the data. By removing the influence of cross-sectional variation in the sample, they provide evidence on marginal (within-site) relationships. Although the international diffusion effects are replicated here, the result for income obviously tells a very different story. Table 5 shows that during the study period, the monitoringsample countries experienced widely-varying changes in income per capita.

\section{Table 5: Statistics for Per Capita Income Growth: Sample Monitoring Sites}

\begin{tabular}{|c|c|c|c|c|}
\hline Minimum & $1^{\text {st }}$ Quartile & Median & $3^{\text {rd }}$ Quartile & Maximum \\
\hline-36.0 & 5.7 & 12.3 & 42.4 & 68.1 \\
\hline
\end{tabular}

Despite this wide variation, the fixed-effect results indicate no marginal responsiveness of air pollution to income. The estimated elasticity is only 0.04 , and it is statistically insignificant.

Table 6 displays estimates for our full model, which includes per capita income, governance, geographic vulnerability, urban population, population density, and pollution-intensive sector share. Cross-sectional relationships are captured in the period regressions, and in the OLS and random-effects regressions on the pooled sample. All of these results tell essentially the same story about average relationships in the data. The governance effect is large and highly significant in all cases. In the pooled random effects model, for example, urban TSP concentration declines about $-.60 \%$ for each $1 \%$ improvement in the Transparency International governance index. Similar results hold for the geographic vulnerability index, which is highly significant in all cases. In the 
Table 6: Determinants of Urban TSP Concentrations

\section{(Matched Monitoring Sites)}

\section{Dependent Variable: Log TSP $\left(\mathrm{ug} / \mathrm{m}^{3}\right)$}

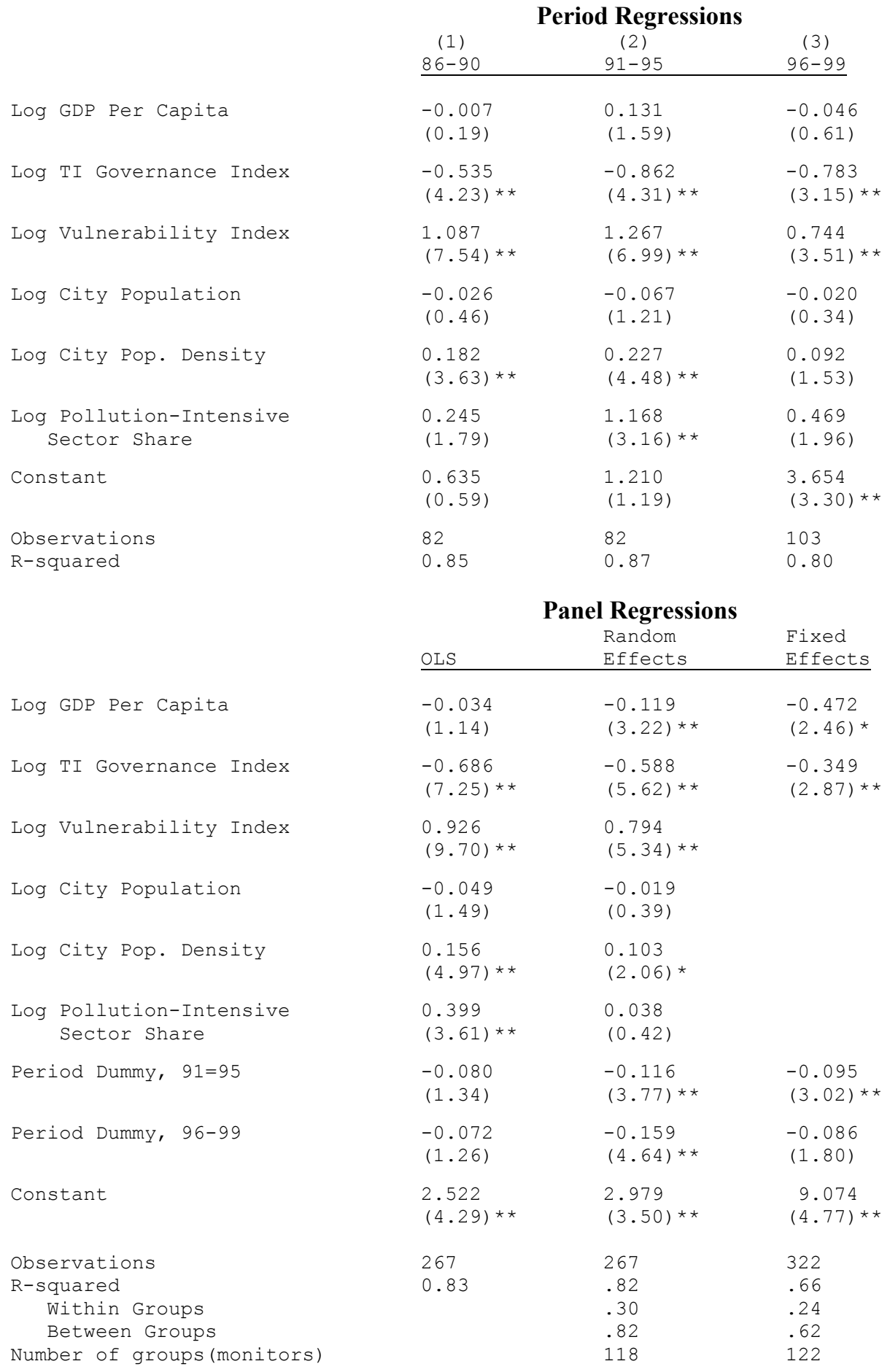

Absolute value of $t$ statistics in parentheses

Significant at $5 \% ; *$ significant at $1 \%$ 
random effects model, TSP concentration increases about $.8 \%$ for each $1 \%$ increase in vulnerability. The results for pollution-intensive sectors are more varied, although the coefficients are always positive, and highly significant in two of five cases. Population does not enter significantly, but population density is significant in four of five equations. The period dummies are negative and significant in the random effects equation, with magnitudes similar to those in the simple EKC results.

For this paper, the most important result is the reduced role of per capita income in the more fully-specified model. Income loses all significance in four of the five crosssectional regressions, and even where it is significant (in the random effects equation), its estimated elasticity is about one-fourth of its value in the conventional EKC estimates. In the cross-sectional model, the strength of the EKC relationship is substantially reduced by the inclusion of governance, geographic vulnerability, sectoral pollution-intensity and urban population. Governance and vulnerability seem to be particularly important factors.

Again, however, the fixed-effects estimates in Table 6 tell a different story at the margin. Since the fixed-effects model introduces site-specific controls, we cannot estimate separate effects for two fixed factors - vulnerability and population density. However, we can assess the impact of marginal changes in income and governance at the monitoring sites in our sample. Once we control for governance, income re-emerges as a significant factor: The estimated income elasticity of air pollution is about -.50 , and significant at the 5\% level. At the margin, the fixed-effect result suggests that urban TSP concentration declines about $.5 \%$ for each $1 \%$ increase in per capita income. The estimated effect for governance remains highly significant, with a somewhat smaller 
magnitude than in the five cross-sectional equations. The period diffusion effects are smaller in the fixed-effect result, and the significance of the late-90's effect is lower.

To summarize, in cross-sectional EKC regressions, inclusion of governance, vulnerability and other variables drastically alters (indeed, effectively eliminates) the conventional EKC relationship. In the fixed-effects model, on the other hand, controlling for governance changes the estimated marginal income elasticity of TSP concentration from negligible (in Table 4) to quite strong (Table 6). At the same time, the importance of governance is suggested by both the cross-sectional and fixed effects results.

\section{Determinants of Urban Air Pollution: Present and Future}

Using our econometric results, we perform two sets of simulation experiments to assess the relative impact of income, governance, vulnerability and population on urban air pollution. For the simulations, we have re-estimated the regressions after dropping insignificant variables.

\subsection{Comparative Impacts}

In the first set of experiments, we use the random effects model to predict air pollution levels for cities whose characteristics represent low, medium and high values of the four determinants. Table 7 displays the relevant ranges from the sample dataset.

Table 7: Simulation Range for Random Effects Results: Characteristics of Non-OECD Cities

\begin{tabular}{|l|c|c|c|c|}
\hline & $\begin{array}{c}\text { Income per } \\
\text { Capita } \\
\text { (\$US) }\end{array}$ & $\begin{array}{c}\text { TI } \\
\text { Governance } \\
\text { Index }\end{array}$ & $\begin{array}{c}\text { Locational } \\
\text { Vulnerability } \\
\text { Index }\end{array}$ & $\begin{array}{c}\text { Population } \\
\text { Density } \\
\text { (/sq. km.) }\end{array}$ \\
\hline Low & 250 & 1.5 & 15 & 100 \\
\hline Medium & 1,000 & 4.5 & 50 & 5,000 \\
\hline High & 8,000 & 7.5 & 85 & 40,000 \\
\hline
\end{tabular}


To assess the partial effect of each determinant, we establish the baseline TSP concentration for a city with "worst-case" conditions (income $\$ 250$, governance 1.5 ; vulnerability 85 , population density $40,000 / \mathrm{sq} . \mathrm{km}$.). For the period 1996-99, the random effects equation predicts an airborne TSP concentration of $437 \mathrm{ug} / \mathrm{m}^{3}$ for this case approximately nine times the current median TSP concentration for OECD cities. From the baseline, we use the random effects equation to predict the partial effect as the four determinants are increased to medium and high levels. Table 8 presents the results.

Table 8: Partial Impacts on TSP Levels

\begin{tabular}{|l|r|r|r|r|}
\hline $\begin{array}{c}\text { Index } \\
\text { Level }\end{array}$ & Income & Governance & $\begin{array}{c}\text { Locational }_{\text {Advantage }} \\
\text { Ad }\end{array}$ & $\begin{array}{c}\text { Population } \\
\text { Dispersion }^{\mathrm{b}}\end{array}$ \\
\hline Low & 437 & 437 & 437 & 437 \\
\hline Medium & 350 & 280 & 302 & 342 \\
\hline High & 252 & 228 & 131 & 216 \\
\hline
\end{tabular}

\footnotetext{
${ }^{\mathrm{a}}$ Measured as declining vulnerability index values $(85=>50=>15)$

${ }^{\mathrm{b}}$ Measured as declining densities $(40,000=>5,000=>100)$
}

For consistent interpretation in Table 8, we invert the measures of geographic vulnerability (to "locational advantage") and population density (to "population dispersion"). Among the four determinants, locational advantage clearly has the greatest impact across its range in the sample data. Holding income, governance, and population density constant at "worst-case" levels, changing locational advantage from low to high reduces predicted air pollution from 437 to $131 \mathrm{ug} . / \mathrm{m}^{3}$. This result suggests that geographic factors alone are sufficient to determine whether a poor, overcrowded, poorly-governed city will suffer from crisis-level air pollution, or experience pollution near the upper bound for air pollution in OECD cities (see Table 11). The other three determinants have major impacts on the TSP concentration, with similar orders of 
magnitude in the transition from low to high values. TSP falls from 467 to 252 for income, to 228 for governance, and to 216 for population dispersion.

Table 9 adds another perspective, by measuring the joint impacts of TSP determinants. For jointly low, medium and high values, governance and locational advantage reduce TSP from 437 to 194 and 69. In combination, all four determinants reduce TSP from 437 to 122 and 20 for medium and high values. Thus, the econometric evidence suggests that air pollution near the OECD median could be attained by a developing-country city with excellent governance and strong locational advantage. When all four determinants take on high values, simulated TSP falls to a level well below the OECD median.

Table 9: Joint Impacts on TSP Levels

\begin{tabular}{|l|c|c|}
\hline & \multicolumn{2}{|c|}{$\begin{array}{c}\text { TSP Determinants: } \\
\text { Joint Effect }\end{array}$} \\
\hline $\begin{array}{c}\text { Joint Index } \\
\text { Values }\end{array}$ & $\begin{array}{c}\text { Governance } \\
+ \text { Location }\end{array}$ & $\begin{array}{c}\text { Income, Governance, } \\
\text { Location, Pop. Density }\end{array}$ \\
\hline Low & 437 & 437 \\
\hline Medium & 194 & 122 \\
\hline High & 69 & 20 \\
\hline
\end{tabular}

We should stress that these results are not artifacts of our regressions. They reflect actual patterns of variation in the urban air quality data. The comparative statistics in Table 11 show that many non-OECD cities already have air quality that falls within the current range of OECD TSP concentrations (15-109). Our econometric analysis has suggested why this should be the case: Despite high levels of poverty and frequent crowding, many non-OECD cities have benefited from good governance and locational advantages that have given them low vulnerability to air pollution. Nevertheless, as the distributional statistics for 1996/99 make clear, at least 75\% of non-OECD cities 
currently have TSP concentrations that would be considered crisis levels in the OECD.

Problems with governance and vulnerability explain a major part of this disparity.

\subsection{Predictions for $\mathbf{2 0 2 5}$}

In the second set of experiments, we predict future TSP levels under alternative assumptions about the time paths of three pollution determinants in our sample cities. In the baseline experiment, we use trends during the 1990's in each city to forecast income, governance and population in 2025. With these forecast values, we predict TSP levels in 2025 for both random and fixed-effects models. In the "policy reform" experiment, we assume that real per capita income grows at a 5\% annual rate in each sample country; the governance index reaches the current $25^{\text {th }}$-percentile value for OECD countries; and the growth rate of the urban population is one-half of the actual rate during the period 19952000. Figures $1 \mathrm{a}$ and $1 \mathrm{~b}$ display the results for the random and fixed-effects models, and Table 11 summarizes the same information, along with comparative statistics for OECD cities in the sample dataset.

The baseline prediction reflects the assumption that recent trends at each monitoring site will continue through 2025. As Table 10 shows, not all of these trends are favorable.

Table 10: Trends in Determinant Values

\begin{tabular}{|l|r|r|r|r|r|}
\hline & Minimum & $\begin{array}{c}1^{\text {st }} \\
\text { Quartile }\end{array}$ & Median & $\begin{array}{c}3^{\text {rd }} \\
\text { Quartile }\end{array}$ & Maximum \\
\hline $\begin{array}{l}\text { Per Capita Income: \% Change, } \\
\text { 1986/90 - 1996/99 }\end{array}$ & -58.3 & -12.1 & 7.8 & 42.4 & 117.7 \\
\hline $\begin{array}{l}\text { TI Governance Index: Change, } \\
\text { 1986/90 - 1996/99 }\end{array}$ & -2.4 & -1.9 & -0.5 & 0.4 & 1.9 \\
\hline $\begin{array}{l}\text { City Population: \% Change, } \\
\text { 1995-2000 }\end{array}$ & -7.1 & 1.9 & 13.0 & 15.0 & 26.7 \\
\hline
\end{tabular}

According to the TI index, over half the sample non-OECD sites were in countries with declining governance quality in the 1990's. While income grew rapidly in some 
countries, it also deteriorated markedly in others, and the median real income gain $(7.8 \%$ for nearly a decade) was quite modest. Urban population continued to grow rapidly in many sample countries, with a median increase of 13\% during the period 1995-2000. Under these conditions, we would expect a mixed set of site-level baseline projections for TSP through 2025. A positive element in our regression-based model is the secular trend downward in overall air pollution from the diffusion of clean technology and environmentalism. We assume that this trend will continue until 2025.

Under the baseline assumptions, Table 11 shows that our random effects predictions anticipate very modest improvements through 2025 , and the fixed-effects predictions are somewhat more optimistic. Across the sample non-OECD cities, the median TSP level falls from 161 to 133 in the random-effects results, and to 119 in the fixed-effects results. The difference is more noticeable in the upper tail of the distribution: The maximum level changes little for random effects, but declines from 470 to 378 for fixed effects. For either model, the baseline predictions are still far from current OECD levels by 2025.

In the policy reform scenario, however, conditions improve markedly. Median TSP falls to 91 for random effects and 71 for fixed effects - both within the current range for OECD cities. Maximum levels also fall markedly (to 248 and 193, respectively), and in the fixed-effects case, $75 \%$ of non-OECD cities have reached the current OECD range by 2025. This prediction reflects assumptions that, while optimistic, are by no means out of reach for many developing countries. We conclude that, despite the geographic vulnerability of many developing-country cities, a quarter century of sustained growth and governance reform could bring them within range of the air quality currently enjoyed by most people in the OECD countries. 
Table 11: Historical and Predicted TSP Levels, 1986 - 2025 (Percentiles)

\begin{tabular}{|l|c|c|c|c|c|c|c|}
\hline & \multicolumn{7}{|c|}{ Non-OECD Cities: Historical Statistics } \\
\hline & Minimum & $10 \%$ & $25 \%$ & Median & $75 \%$ & $90 \%$ & Maximum \\
\hline Non-OECD TSP, 1986-90 & 59 & 76 & 133 & 220 & 345 & 503 & 560 \\
\hline Non-OECD TSP, 1991-95 & 45 & 74 & 112 & 214 & 329 & 464 & 728 \\
\hline Non-OECD TSP, 1996-99 & 9 & 59 & 82 & 161 & 256 & 368 & 470 \\
\hline & \multicolumn{7}{|c|}{ Random Effects Predictions } \\
\hline Non-OECD TSP 2025 (Baseline) & 10 & 49 & 70 & 133 & 245 & 373 & 464 \\
\hline Non-OECD TSP2025 (Reform) & 4 & 31 & 51 & 91 & 136 & 193 & 248 \\
\hline & \multicolumn{7}{|c|}{ Fixed Effects Predictions } \\
\hline Non-OECD TSP 2025 (Baseline) & 9 & 46 & 70 & 119 & 195 & 272 & 378 \\
\hline Non-OECD TSP2025 (Reform) & 3 & 24 & 39 & 71 & 105 & 149 & 193 \\
\hline & \multicolumn{7}{|c|}{ OECD Cities: Historical Statistics } \\
\hline OECD TSP, 1986-90 & 23 & 38 & 42 & 58 & 83 & 122 & 206 \\
\hline OECD TSP, 1991-95 & 21 & 28 & 36 & 49 & 62 & 95 & 136 \\
\hline OECD TSP, 1996-99 & 15 & 24 & 32 & 42 & 49 & 64 & 109 \\
\hline
\end{tabular}

\section{Summary and Conclusions}

In this paper, we have revisited the environmental Kuznets curve for air pollution, using new data on the determinants of air quality. Using a balanced panel of air monitoring data for the period 1986-1999, we have estimated air quality models that control for governance, vulnerability, population density and pollution-intensive economic activity, as well as income per capita. Our econometric results show varied impacts for income, but they are unambiguous in their assignment of importance to governance and geographic vulnerability. Using both random- and fixed-effects estimators, we use simulation experiments to assess the relative importance of income, governance, vulnerability and population density as determinants of air quality. We find that governance and geographic vulnerability alone are enough to account for the crisis levels of air pollution in many developing-country cities. When their effects are combined with those of income and population density, we have a sufficient explanation 
for the fact that some developing-country cities already have air quality comparable to levels in OECD cities.

In another simulation, we project air pollution in 2025 for our sample cities using two sets of assumptions. In the baseline set, we allow current trends to continue for income, governance and population density. This leads to substantial improvement in air quality for the fixed-effects model, and moderate improvements for the random-effects model. In the second set, we assume that policy reforms produce real income growth of $5 \%$ annually, improved governance sufficient to achieve parity with the current lower quartile of OECD countries, and urban population growth at half the rate observed in 1995-2000. In the reform scenario, both random- and fixed-effects models predict sharp improvements in air quality for most developing-country cities. By $2025,75 \%$ have attained air quality within the current range experienced by OECD cities.

In light of these results, we believe that policy makers should be wary of the conventional EKC model. Our results offer no support for the view that air quality deteriorates during the first phase of economic growth. At worst, air quality remains constant, even at very low income levels, and our fixed-effects results suggest that income growth significantly improves air quality at the margin. Nor do our results support the EKC-motivated view that citizens of poor countries necessarily face a long wait for major improvements in air quality. Significantly-improved governance is possible in poor countries, and our results suggest that policy reform alone is sufficient to reduce air pollution by $50 \%$, even in overcrowded, geographically-vulnerable cities in countries with very low incomes. 
Although our results have an optimistic cast, we feel compelled to close with some notes of caution. Our results for geographic vulnerability suggest that increases in air emissions are much more dangerous in some cities than in others. In light of this finding, urban planners may want to take vulnerability into account as they consider national and regional policies for the next round of urban development. We should also note that nothing in our hopeful predictions is preordained. Our results imply that air quality will become worse in cities with stagnating or falling incomes, deteriorating governance, and rapidly-growing populations. And even in the reform scenario, improvements by 2025 cannot save many people who will die from dangerous air pollution during the next quarter century. We see no conflict between urban air quality and economic growth (the converse, in fact), but improved environmental governance seems to provide our best hope for rapid improvement. 


\section{References}

Bonior, D., 1999, "Defending Democracy in the New Global Economy," Statement to an AFL-CIO Conference on Workers' Rights, Trade Development, and the WTO. Seattle, Washington, December.

Daly, H., 2000, "Globalization," Presented at the 50th Anniversary Conference of the Aspen Institute. Aspen, Colorado. August.

Dasgupta, S., Laplante, B., Wang, H., Wheeler, D., "Confronting the Environmental Kuznets Curve," 2002, Journal of Economic Perspectives, Vol. 16, No. 1, Winter.

Esty, D., Cornelius, P., 2002, Environmental Performance Measurement: The Global Report 2001-2002, Oxford Press.

Grossman, G., Krueger, A., 1993, "Environmental Impacts of the North American Free Trade Agreement," in P. Garber (ed.), The U.S.-Mexico Free Trade Agreement (Cambridge: MIT Press, 1993).

Hettige, M., Mani, M., Wheeler, D., 2000, "Industrial Pollution in Economic Development: The Environmental Kuznets Curve Revisited," Journal of Development Economics, 62(2), August, pp. 445-476.

John, A, Pecchenino, R., Schimmelpfennig, D., Schreft, S., 1995, "Short-Lived Agents and the Long-Lived Environment," Journal of Public Economics, 58, 127-141

Lopez, R., 1994, "The Environment as a Factor of Production: The Effects of Economic Growth and Trade Liberalization," Journal of Environmental Economics and Management, 27, 163-184.

López, R., Mitra, S., 2000, " Corruption, Pollution, and the Kuznets Environment Curve," Journal of Environmental Economics and Management, Vol. 40, No. 2, pp. 137-150

Mani, M., Wheeler, D., 1998, "In Search of Pollution Havens? Dirty Industry in the World Economy, 1960-1995," Journal of Environment and Development, Fall.

Marland, G., Boden, T., Andres, R., 2001, "Global, Regional, and National Fossil Fuel CO2 Emissions," Carbon Dioxide Information Analysis Center, Oak Ridge National Laboratory, U.S. Department of Energy, Oak Ridge, Tennessee (available online at $<$ http://cdiac.esd.ornl.gov/trends/emis/meth_reg.htm>).

Hettige, H., Singh, M., Martin, P., Wheeler, D., 1995, “The Industrial Pollution Projection System," World Bank Policy Research Working Paper, No. 1431, March.

McConnell, K.E., 1997, "Income and the Demand for Environmental Quality," Environment and Development Economics, 2(4), 383-399. 
Nader-for-President, 2000, http://www.votenader.com/issues/environment.html.

Pandey, K. D., Bolt, K., Deichmann, U., Hamilton, K., Ostro, B., Wheeler, D., 2004 (forthcoming), "The Human Cost of Air Pollution: New Estimates for Developing Countries," World Bank Development Research Group Working Paper, Washington, DC.

Rauber, P., 1997, “To Every Fruit There is a Season,” Sierra Club Magazine, 82 (1) January/February.

Sagaris, L., 1999, "Not Now, NAFTA: Chile's Economy may be Ready for Free Trade, But Its Environment is Not," Sierra Club Magazine, 84 (1) January/February.

Selden, T., Song, D., 1995, "Neoclassical Growth, the J Curve for Abatement, and the Inverted U Curve for Pollution," Journal of Environmental Economics and Management, 29, 162-168.

Stern, D. I., Auld, A., Common, M., Sanyal, K., 1998, "Is There an Environmental Kuznets Curve for Sulfur?" Working Papers in Ecological Economics, 9804, Center for Resource and Environmental Studies, Australian National University, Canberra.

Stern, D. I., 1998, "Progress on the Environmental Kuznets Curve?" Environment and Development Economics, 3, 175-198.

Wheeler, D., 2001, "Racing to the Bottom? Foreign Investment and Air Pollution in DevelopingCountries," Journal of Environment and Development, September.

World Bank, 2003, World Development Report 2003: Sustainable Development in a Dynamic World, Washington: World Bank/Oxford University Press. 
Figure 1: TSP Distributions in Non-OECD Cities: 1986 - 2025

(1a) Random-Effects Model

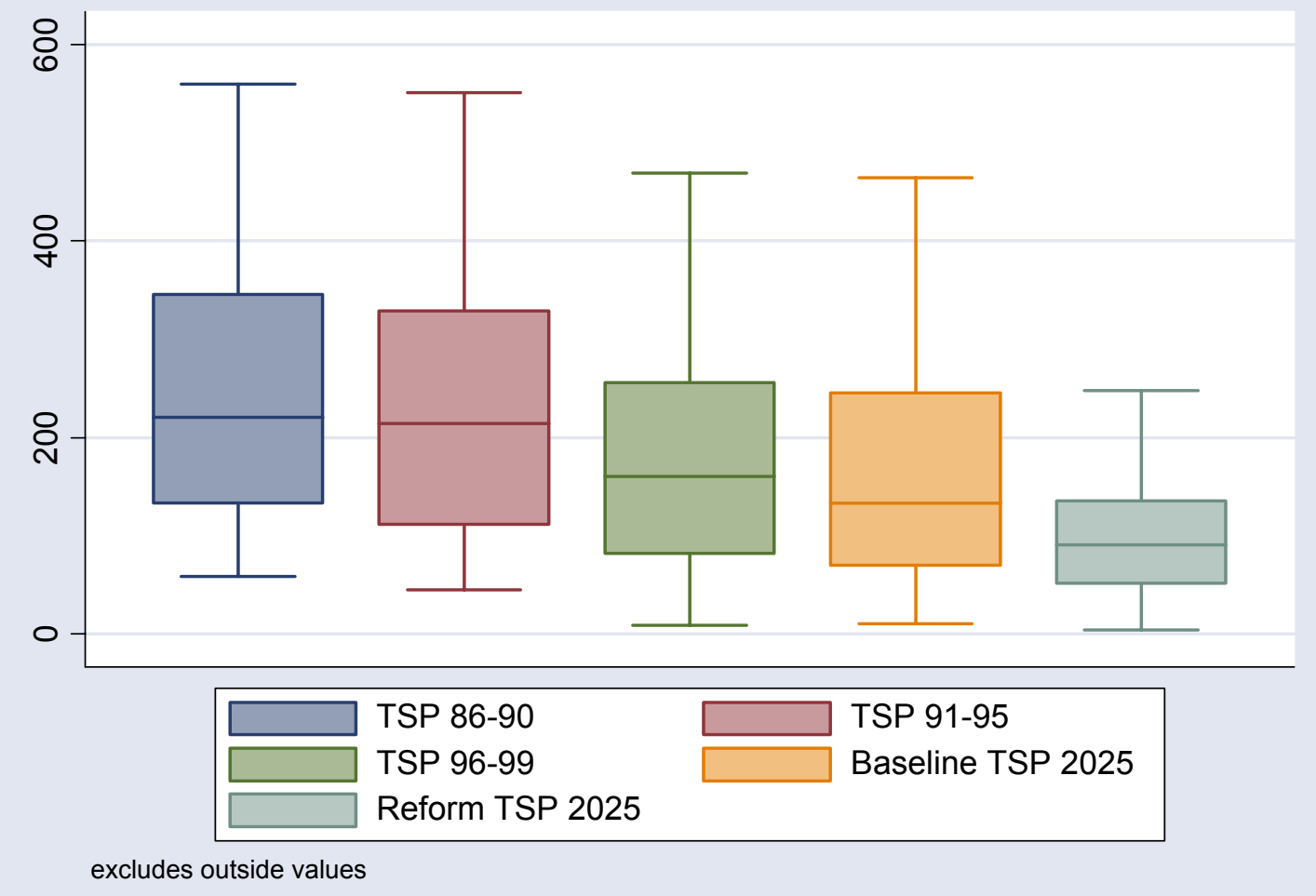

(1b) Fixed Effects Model

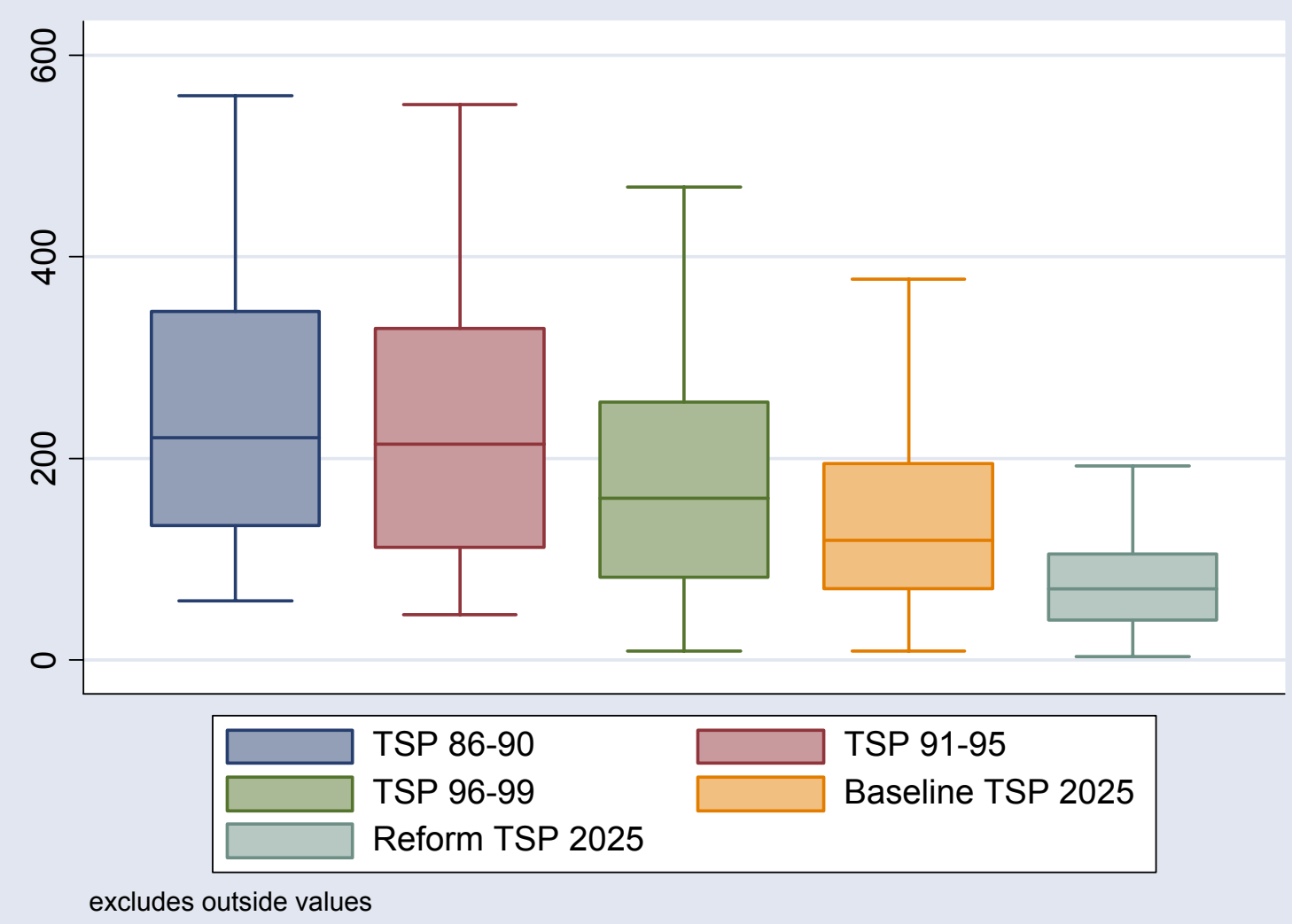

